\title{
URBANISMO Y PROBLEMÁTICA SOCIAL EN CÁDIZ. UNA APROXIMACIÓN HISTÓRICA
}

\author{
José Manuel Mato Ortega
}

\section{RESUMEN}

El artículo es una aproximación al análisis de la sociedad de la Bahía de Cádiz, y específicamente, de la ciudad que le da nombre. Partiendo de los planes de reforma urbana, se estudian: la distancia entre el papel y la realidad, las políticas de rehabilitación, los problemas laborales y de la vivienda, la terciarización, etc. Todo bajo un prisma histórico.

Palabras clave: Cádiz, urbanismo, población, puerto, desarrollo, transporte.

\section{ABSTRACT}

The article is a study about the Cadiz Bay's society, and about this city specially. There are used the urban plans. We're studying: the opposite theory-reality, the restoration politics, the labour and housing problems, the service sector, etc. Everything is under a historic view.

Key words: Cadiz, urbanism, population, harbour, expansion, transport.

\section{INTRODUCCIÓN. CONSIDERACIONES INICIALES}

El interés de este artículo está en analizar algunas de las líneas de continuidad de los proyectos de mejora urbanos durante la segunda mitad del siglo XX. Estas líneas de continuidad, obviamente, se deben a incumplimientos de los mismos. Estos incumplimientos son consecuencia, en algunas ocasiones, de la falta de partidas presupuestarias, en otras, de corrupciones (como veremos), y en un último grupo, de una verdadera ausencia de interés por llevarlas a cabo; una ausencia de interés que convierten a buena parte de esos proyectos en auténtico papel mojado.

Pero estas líneas de continuidad, a un tiempo, son reflejo así mismo de la perseverancia de ciertos usos, problemas y sistemas sociales, que se perpetúan en el tiempo y difícilmente encuentran solución. Son, estas relaciones entre la cuestión urbanística y la problemática social, el verdadero objeto de estudio del presente trabajo. Recordemos que una 
ciudad, por encima de todo, es un espacio poblado; y en última instancia, es esa gente que la puebla, en cualquier estudio urbano que se precie, la verdadera protagonista.

La ciudad de Cádiz, y el entorno de la Bahía, además, por su dilatada Historia, es ideal para realizar un estudio que abarque la evolución de la urbe a lo largo de los siglos; ya que algunos de los problemas, y sus soluciones, se encuentran, si se sabe dónde buscar, en su proyección temporal. Éste es, por ejemplo, el caso de la integración de la Bahía, que, sorprendentemente, y en términos relativos, según limitaciones obvias como la tecnología -fundamental en el análisis-, descubrimos más elaborada en algunos de los momentos del pasado que en la actualidad.

\section{METODOLOGÍA Y ESTRUCTURA DEL ESTUDIO}

Con las consideraciones preliminares como telón de fondo, este artículo está dedicado, fundamentalmente, al estudio histórico del urbanismo gaditano, y a los efectos y carencias de los sucesivos planes de reforma y mejora del entramado y sistema urbano desde 1948. Dos son los temas transversales que recorren toda la obra: la integración de la Bahía y la proyección de futuro de la ciudad. Ambos íntimamente relacionados entre sí y constituyentes de sus propios epígrafes, el segundo acompañado a su vez del apartado de conclusiones.

La metodología seguida corresponde a lectura y análisis de fuentes directas, como los planes urbanísticos del 48 y del 84 (además del Plan URBAN), así como el referido a la Bahía (del año 2002), y a la lectura de obras dedicadas a los asuntos que nos ocupan, tanto históricas como propiamente urbanísticas. También, aunque en menor medida, se ha utilizado prensa escrita y digital.

\section{Intervenciones de rehabilitación y mejora. Problemáticas actuales}

En este apartado analizaremos cuáles han sido las principales directrices seguidas en pos de la rehabilitación de la ciudad de Cádiz. Por las peculiaridades y el legado histórico-cultural del Casco Antiguo ${ }^{1}$, así como por los niveles de deterioro y de precariedad que sus habitantes padecen, veremos cómo ha sido éste, principalmente, el objeto de la mayor parte de las acciones y proyectos.

En pos de comprobar el nivel de correspondencia entre lo proyectado y lo llevado a cabo, se han utilizado, además de la necesaria bibliografía complementaria, tres documentos directos que por su fechado se revelan de importancia, puesto que transmiten los modos de pensar y las prioridades de las autoridades así como, en lo referente a lo realizado, nos informan del devenir de ciertas partes de la ciudad. Así mismo, aquellos proyectos no llevados a cabo son indicativos, en buena medida y según qué casos, de los intereses profundos de las oligarquías dirigentes, al fin y al cabo, las destinadas a dar forma a los planes diseñados y las beneficiarias o no de los mismos.

\footnotetext{
He utilizado indistintamente los términos Casco Antiguo y Centro Histórico. Ello se debe, tanto a la permutación indiscriminada de ambos términos por parte de la población de la ciudad, como a la misma falta de precisión observada en la bibliografía y fuentes utilizadas.
} 
Por otro lado, esta documentación original generalmente suele justificarse alegando tres tipos de problemáticas: el deterioro del paisaje urbano, las dificultades y obstáculos económicos, y la realidad social de las clases pauperizadas. El distinto orden en que estas son presentadas, así como la prioridad otorgada a ciertos elementos por encima de otros en las soluciones propuestas, son fiel reflejo también de las mentalidades con las que trabajamos.

\subsection{Análisis de las fuentes desde una perspectiva histórica}

Así pues, hemos trabajado con tres documentos de tres épocas que consideramos representativas dentro de la segunda mitad del siglo XX: el Plan General de Ordenación de la Ciudad de Cádiz de 1948, el Plan Especial de Protección y Reforma Interior del Casco Antiguo de Cádiz de 1984, y el Plan Urban de 1997. Por sus características especiales podríamos haber incluido también el Plan de 1961, sin embargo hemos prescindido del mismo, ya que, como otros planes, fue vulnerado, y además, especialmente, inserto como estaba en plena época de la política desarrollista ${ }^{2}$. Consideramos, por otra parte, que conclusiones acerca de los efectos de ésta, se hayan en el Plan de 1984, así como en la bibliografía crítica respecto a la misma.

El Plan de 1948 corresponde aún al periodo de Autarquía y en concreto se enmarca en el contexto de la explosión del 47. De hecho, el titular del proyecto es el de "Comisario para la reconstrucción de Cádiz". Podemos observar una serie de elementos que nos hablan de las líneas políticas de la época, como la relevancia del nacionalcatolicismo ${ }^{3}$, a la vez que observamos algunas preocupaciones propias del régimen y que podemos enlazar con la etapa posterior al Plan de Estabilización del 59, como son la preocupación por el desarrollo industrial y la orientación de Cádiz hacia el sector servicios ${ }^{4}$.

En el Plan de 1984, sin embargo, encontraremos una mayor preocupación por la situación socioeconómica de la población gaditana ${ }^{5}$, y un cierto afán de mejorar las estruc-

JIMÉNEZ y MALO: 95, pp. 93-97.

En la página 14 del mismo se consideran edificios públicos de necesidad fundamental: "parroquia, centros comercial, mercado, deportes, garages (sic), etcétera”. Y en la página 11 se indica en relación a la manera en la que se han de ordenar los barrios: "organizando en cada uno de ellos su centro cívico como lugar de emplazamiento de los edificios que le son necesarios principalmente la Iglesia y el Mercado”. MINISTERIO DE LA GOBERNACIÓN: 48.

4 Siguiendo con el desciframiento de la mentalidad del régimen a través de sus documentos, es de reseñar, la impunidad de la que se hace gala al afirmar, en relación con la necesidad de urbanizar extramuros, el destino del "segundo (barrio) para viviendas principalmente modestas." (Ibíd. p. 12). El régimen no tiene reparos en confesar su pretensión de inamovilidad y de conservación a ultranza del orden; en este sentido, al menos, es sincero. Nos ilustra también al respecto de la mentalidad productivista el proyecto portuario de 1951 en el que "se pretende ayuda financiera para la construcción de viviendas" (en base al Decreto-Ley de Viviendas Bonificables de 19 de Noviembre de 1948) a pie de obra. BARRAGÁN: 95, p.81. La idea de crear viviendas populares en Extramuros, en coincidencia con proyectadas instalaciones fabriles, y contrastando con la existencia de áreas vacías en el Centro, estaba ya presente en los planes del cabildo de 1906. MARCHENA: 96, pp.118-121.

5 Esta nueva actitud de las administraciones se constata en el hecho de que el Plan del 84 toma como punto de partida una encuesta realizada por el cabildo a la ciudadanía y que versaba sobre las principales preocupaciones de ésta respecto a su ciudad. Resultados de la misma (aparecidos en el Boletín de Información Municipal de Abril de 1984) son: la vivienda (poco higiénicas y caras), que afecta sobre todo a los jóvenes de extracto popular; los servicios urbanos, ante todo la limpieza y la vigilancia, a la que echan en falta las amas de casa y los ancianos (recordemos 
turas urbanas, orientado teóricamente a la mejora de la misma. Esto se entiende en relación con el incipiente andar de la Democracia y con el papel jugado en la época por el PSOE, inmerso en sus "años rojos". Como telón de fondo de estas iniciativas podemos tener también en consideración la proximidad de los fastos conmemorativos del Quinto Centenario, en el que Cádiz, por su relación histórico-cultural con América, estaba llamada a jugar un papel destacado. En este Plan, y por seguir con el análisis político del momento, encontramos también las primeras referencias a Europa y a que España ha de seguir su ejemplo $^{6}$, no en vano, el año 86, esto es, catorce meses después, España entra como socio en la CEE.

Esto nos sirve para enlazar con el Plan Urban. Por un lado, el color político gobernante tanto en el Estado como en la ciudad ha cambiado (en lugar del PSOE, gobierna ahora el PP, desde el 95 en Cádiz, y desde el 96 en España); por otro, hay una clara línea de continuidad entre el Plan del 84 y el Plan Urban, ya que éste es fruto de una iniciativa de la UE, que en estos años ha seguido profundizando en cohesión interna. Las líneas de continuidad respecto a la etapa anterior son, pues, varias: por un lado, poco dista el PP, sobre todo en la primera legislatura, sin mayoría absoluta, del PSOE de los 90, pues ambos defienden ya abiertamente, desligado el PSOE del marxismo, las políticas neoliberales en boga. Por otro, Andalucía era, y sigue siendo, una de las regiones consideradas de prioridad 1 para la UE, en cuanto a la necesidad de invertir en su desarrollo. Ligado con esto, Cádiz se ha mantenido como la capital europea del paro (posiblemente hasta la apertura al Este del 5 de Mayo de 2004), lo cual tiene una serie de consecuencias a nivel social y, por ende, urbano.

\subsection{La realidad socioeconómica gaditana. Una eterna cuestión}

\subsubsection{La estructura de la población. Generalidades}

Toda aproximación a la problemática urbanística de una ciudad pasa forzosamente por un estudio más o menos pormenorizado sobre la distribución socioeconómica de la población. Y ello por varios motivos:

a) La población con niveles de renta más bajos suele hallarse hacinada en barrios y zonas deterioradas; o lo que es lo mismo, la población de altos ingresos, tiende a acomodarse allí donde los servicios urbanos y la calidad y amplitud de las casas son más elevadas. Estas zonas marginales constituyen un quebradero de cabeza para las autoridades tanto en el aspecto de la rehabilitación urbana, cuyos planes suelen, precisamente, por la escasa importancia económica de los afectados y por los niveles de incultura que padecen, quedarse en el papel, como por los proble-

que esta época marca una alta cota de índice de heroinómanos en la ciudad); y por último, falta de infraestructuras escolares adecuadas, y de parkings, o más bien, protestas por el estacionamiento de vehículos rodados en las aceras. Así mismo se afirma en la Introducción, explícitamente, que se trata de crear "una ciudad para los ciudadanos". AYTO DE CÁDIZ: 1984, p. 3.

6 De este modo, en la Introducción del Plan, firmada por el entonces alcalde, Carlos Díaz, se hace referencia a las políticas europeas respecto a la ciudad, basadas en una actitud reflexiva en contra de "invasiones culturales" y recelosa de la "sociedad consumista". (Ibíd. p.3) 
mas de inseguridad y las competencias de control que se derivan de esta misma situación ${ }^{7}$.

b) Las políticas de rehabilitación suelen estar enfocadas a la puesta al día, la mejora, de los centros históricos. Estos padecen habitualmente una pérdida de la mezcla social característica de su propia evolución. Las oligarquías locales suelen ser afectadas por un efecto expulsión, quedando los centros habitados por dos grupos diferenciados: ancianos y marginados (más adelante, abordaremos las peculiaridades de la ciudad de Cádiz); y, en una segunda fase, aprovechando las mejoras propiciadas por los diferentes impulsos institucionales en pos de la rehabilitación de los centros, por urbanitas de rentas altas que compartirán el espacio con los primeros, pero diferenciándose convenientemente, sin integración.

c) Asimismo, los centros históricos se ven afectados por movimientos especulativos, que generalmente se dividen en dos actos:

c.1. El propietario bien se arma de paciencia, bien presiona a los inquilinos para que abandonen la casa ${ }^{8}$.

c.2. Una vez vacía, la reserva y la mantiene deshabitada a la espera de dos posibles efectos: el deterioro al que se ve abocado la finca puede determinar la actuación de la administración en pos de su rehabilitación, tras lo cual, con la reforma efectuada ${ }^{9}$, podrá volver a arrendarla a mayor precio; o bien, el mantenimiento de varias fincas deshabitadas encarece el suelo en la ciudad, por lo cual consigue el propietario desesperar al mercado inmobiliario y convertir su propiedad en un precioso objeto deseado por posibles compradores y arrendatarios.

d) En los Planes se contempla, generalmente, el proceso rehabilitador como generador de empleo y alivio para estos sectores pauperizados de la población y afectados por altos índices de paro. En general los planes urbanos se plantean también el relanzamiento de las actividades económicas en la ciudad.

\subsubsection{Particularidades}

Cádiz, aun compartiendo estas características fundamentales con el resto de Centros Históricos, posee algunas peculiaridades relacionadas con el comportamiento de las élites urbanas.

a) Aunque buena parte de las familias de mayores ingresos han fijado su residencia fuera del Casco Antiguo, Cádiz es aún heredera de la estructura del siglo XIX ${ }^{10}$, y mantiene en el mismo a sectores importantes de su oligarquía.

Las más de las veces la solución adoptada es la profundización en el gueto, evitando eso sí, la infiltración y extensión de los problemas y conflictos a las zonas lindantes con los mismos. Un caso ilustrativo de esto es el barrio de las Tres Mil Viviendas de Sevilla, condenado y dejado a su suerte por las autoridades.

8 En relación con esto, es difícil dejar de comentar la actuación de los conocidos popularmente como asusta viejas, que se han constituido como un problema social de primer orden y de cuyos tejemanejes ha quedado constancia en las sesiones plenarias y en los tira y afloja de la política municipal durante este verano de 2005 .

9 También puede producir otro efecto, menos deseado por los propietarios y también menos habitual en cuanto que la propiedad, tal y como se ha demostrado con la orden de tirar a matar a los saqueadores tras los efectos del huracán Katrina en EEUU, es poco menos que inviolable en los sistemas demoliberales: la expropiación con indemnización o sin ella (en casos muy extremos de dejadez por parte del propietario).

10 Esta estructura, que comienza a fijarse ya en la Edad Moderna, grosso modo se define por: la ubicación de las clases más desfavorecidas en la fachada atlántica del Casco, y la de las familias pudientes in crescendo desde la Bahía 
b) Pese a ser materia del tema siguiente, no huelga hacer notar aquí también, que dadas las características de la Bahía, una parte importante de las oligarquías gaditanas (viejas y nuevas) y también de las clases medias acomodadas, ya como primera ya como segunda residencia, se han instalado en el hinterland de la ciudad.

Para este punto, es especialmente interesante el estudio realizado por Acosta Seró. Éste, atendiendo a un buen número de variables ${ }^{11}$, divide el Casco Antiguo en siete clústeres.

\subsubsection{Soluciones a la situación económica de la ciudad. La industria y el turismo}

Es interesante observar cómo ha ido variando el diseño de las soluciones a aplicar ante la problemática económica de la ciudad. Estas soluciones, lógicamente, son fruto de los distintos intereses que han entrado en juego en un momento u otro, así como de las perspectivas y enfoques al futuro de la ciudad que, según la coyuntura, ha parecido más conveniente aplicar.

Hasta la década de los 60 del siglo pasado, el futuro económico de la ciudad se ha vinculado con el puerto. En su remodelación, mejora y relanzamiento cifraron muchos gaditanos sus esperanzas de ver a la ciudad recuperar su papel preponderante en el comercio exterior español, y en concreto, el intercambio con América Latina. Relacionado con ello, se encontró siempre la aspiración a la concesión de la categoría de Puerto Franco ${ }^{12}$.

Significativo es la certeza que en este sentido sostiene el Plan de 1948. En el mismo, además de en la reconstrucción de lo arrasado por la explosión, se hace hincapié en la necesidad de mejora de las comunicaciones de la ciudad, y en este sentido se atiende tanto al Casco como a, y en mayor medida, Extramuros. En relación con el tráfico de mercancías en dirección al puerto, se idea la carretera de Astilleros para descongestionar el tráfico de la Avenida de la presencia de vehículos pesados. Esto se puso en relación con el futuro desarrollo industrial al este de la vía de ferrocarril, de la que, sin embargo, debido a los movimientos especulativos del franquismo, sólo se realizaría la actualmente denominada Zona Franca ${ }^{13}$.

(Constitución, especialmente, San Carlos y San Francisco y Correo) hacia el interior, destacando la Calle Ancha (antiguo barrio o distrito de Cortes).

11 Estas variables, veintidós en total, son: número de habitantes por vivienda, tasa de crecimiento de la población, porcentaje de población entre 0 y 14 años y mayor de 65 , porcentaje de desempleados de población ocupada y de estudiantes (así como el de población con titulación universitaria), porcentaje de viviendas sin baño, sin cocina, sin retrete interior y sin teléfono; porcentaje de edificios de uso no residencial catalogados como susceptibles de protección, como monumentales, como singulares, como preferentes y como ambientales; porcentaje de viviendas construidas antes de 1941 y entre 1971 y 1991; porcentaje de viviendas en propiedad y proporción de comercios minoristas por edificio. ACOSTA: 98.

12 En realidad, pese a la idea popular al respecto, ya a altura de 1903, Viniegra, antiguo concejal del Ayuntamiento, consideraba más positivo, tras analizar los resultados del puerto franco entre 1820 y 1832 , y con el proyecto a Cortes presentado por Barcelona ese mismo año como precedente (MARCHENA: 96, pp. 76-77) que la liberación de tarifas afectara sólo a un área del puerto, entendiéndolo más rentable que la concesión de esta categoría a todo él. De esta interpretación del asunto (y de la posterior perseverancia de Ramón de Carranza), es heredera la actual Zona Franca.

13 El suelo industrial en el resto de Andalucía ha venido, en general, sufriendo el mismo destino que el de Cádiz. El modelo típico de polígono industrial extraurbano fue impulsado con la política de los polos de desarrollo, que intentó, sin éxito, configurarse en acicate para la iniciativa privada mediante incentivos financieros y fiscales; pero pronto, espoleada por la crisis económica de los 70, el criterio imperante fue la rápida enajenación de ese suelo 
Sobre la posibilidad de utilización de Extramuros como lugar propicio para la ubicación de instalaciones industriales, tenemos un ejemplo ya en 1895: "terrenos que una vez expropiados por el Municipio, podían ser ofrecidos a las sociedades ó empresas que deseasen instalar alli sus industrias, urbanización que por todos conceptos favorecerían a la ciudad, (..)El indicado medio no sólo es de inmediata ejecución, sino de importancia suma para el desarrollo industrial de Cádiz..." ${ }^{14}$ Esta preocupación por el puerto de la ciudad parece decaer, y con la conclusión del puente José León de Carranza en 1969, se consiguió cubrir por el momento y hasta la actualidad las necesidades de acceso a Cádiz.

Sobre las comunicaciones también nos ofrece el Plan del 48 la idea de la construcción de una carretera por el margen atlántico del istmo. Esta carretera, junto a la puesta al día del Campo del Sur, se presenta como un medio de potenciar lo que en el futuro ha devenido en actividad económica más importante de Cádiz, abandonado el ideario desarrollista, del que la ciudad es desplazada con la constitución de las áreas de preferente industrialización en el año $1964^{15}$.

En el plan del 84 apenas si se encuentran referencias al puerto o a la industria (más allá de la mención sobre los pequeños talleres del centro y las reflexiones acerca del paro y el subempleo en la ciudad). Esto se debe, sin duda, al hecho de que se trata de un Plan para la rehabilitación del casco histórico tras años de abandono y tras la modalidad urbanística de los años 60 y 70, "expansiva, despilfarradora y destructora de la ciudad (que) sólo beneficiaba a unos pocos y ha sembrado de conflictos sociales nuestras ciudades." ${ }^{16}$ Pero junto a estos motivos, hemos de tener en cuenta el abandono de la idea y posibilidad de un Cádiz industrial, habida cuenta del mal uso del suelo de Extramuros (ahogado por la especulación y el amiguismo) y de la asignación de un papel muy concreto a España en la división mundial del trabajo ${ }^{17}$. En esta situación, a la ciudad de Cádiz sólo le queda como recurso económico convertirse en polo de atracción turística.

En el plan del 48 ya se observan medidas en este sentido. Una que resulta llamativa es la "creación de un barrio de turismo de carácter residencial con los edificios complementarios y zonas de deporte convenientes" 18 , "en las proximidades del Balneario y a base de núcleo intensivo de altura"19.

público mediante agentes privados y con escasa transparencia, lo que condujo al "acaparamiento, con fines especulativos, por agentes inmobiliarios no destinados a la producción industrial". FERIA: 94.

14 GARCÍA: 1995, p. 43- reedición a cargo de Barragán y Torrejón-.

15 No obstante, en el período 1960-1973, la economía gaditana, aun por debajo de la media nacional, creció más que la andaluza. La expansión, sin embargo, se hizo en base a la especialización en sectores en los que se carecían de ventajas comparativas y en un proceso de previsible crisis. El punto de inflexión a la baja tiene lugar en 1973, e irremediablemente se produce la crisis industrial de 1977, dándose la circunstancia de que la ciudad y su Bahía estaban especializadas, precisamente, en los sectores más castigados por la misma. Además, "la caída de la demanda (...) coincide con un periodo en el que (...) se encontraba en fase de expansión de su oferta" RUIZ: 87, p.20.

16 AYTO DE CÁDIZ: 1984, p.3. Obviamente en este tipo de declaraciones se debe percibir la intención de distanciarse y oponerse al régimen anterior.

17 Como requisito a la entrada en la CEE España tuvo que desmantelar su industria para que no fuese competitiva dentro del mercado único con la alemana o la francesa; así, se explican las reconversiones industriales. Recordemos, por ejemplo, la crisis de Astilleros de 1987.

18 MINISTERIO DE LA GOBERNACIÓN: 48, p. 7.

19 Y continúa: “(...) con sus edificios públicos (Iglesia, Mercado, Campo de Deportes, etcétera)” (Ibíd. p. 12), siendo reflejo el texto, una vez más, de las ideologías imperantes en el régimen, ya que, como se aprecia, no olvida nunca el referente religioso. Sobre el barrio turístico en torno al Hotel Playa se expresa: "La idea es la de 
Sin embargo, las posibilidades de Cádiz como zona turística de sol y playa son limitadas $^{20}$, por lo que pronto se observa un giro hacia su potencialidad como centro de recepción del turismo cultural ${ }^{21}$. La elección de esta vía, dentro de la reducción que supone para la población de sus opciones profesionales al servicio, es menos destructora del medio y de la cultura del lugar, y al tiempo, significa, de hecho, una mejora del entorno urbanístico y, por ende, de la calidad de vida del ciudadano. Además, obviamente, no responde sólo a un interés económico, sino también a una verdadera preocupación por el legado patrimonial ${ }^{22}$; aunque esto no tiene, necesariamente, que revertir en la población. Por un lado porque la rehabilitación de los cascos históricos, aunque soluciona problemas de infraestructura a sus habitantes, frecuentemente, como vimos antes, de extracción social baja, abandona a su suerte a los habitantes de las zonas marginales de la periferia (en el caso de la ciudad de Cádiz, la Barriada de la Paz o el Cerro del Moro, por ejemplo). Por otro lado, porque ni aún en los cascos históricos constituyen, las intervenciones de rehabilitación ${ }^{23}$, una garantía para los residentes en cuanto a la mejora de sus condiciones de vida; un acercamiento a la legislación emanada de las distintas administraciones confirmará lo que decimos:

a) Leyes estatales.

a.1) Ley del Suelo y de Ordenación Urbana del año 56. Orientada hacia el desarrollismo.

a.2) Real Decreto 2329/83 de 23 de Julio. Preocupación por el empleo y el problema de la expulsión de residentes como consecuencia de la mejora de los centros y la subsiguiente atracción de rentas más elevadas.

a.3) Real Decreto 1932/91 de 20 de Diciembre. Se centra en la rehabilitación estructural.

a.4) Real Decreto $2190 / 95$ de 28 de Diciembre. Reconoce el fracaso de las medidas adoptadas hasta la fecha y se muestra mayor interés en el interior de las viviendas que en las fachadas. ${ }^{24}$

crear una serie de edificaciones de doble crujía en forma de boques abiertos redondeados en zonas ajardinadas y suficientemente espaciados para lograr las mejores condiciones de soleamiento y puntos de vista." (Ibíd. p. 14) Esta voluntad expresa por construir viviendas saneadas para la recepción turística contrasta con lo señalado en la Nota 4.

20 Además, recordemos que es la costa malagueña la que sufre el impacto turístico desarrollista unos años más tarde (tomando como referencia 1948); para bien y salvaguardia de las costas gaditanas, que, lamentablemente, están siendo objeto en los últimos años, saturada la Costa del Sol, de un proceso similar, aunque mitigado por los efectos que sobre el turista centroeuropeo está teniendo la paulatina desestructuración del Estado del Bienestar.

21 Desde antiguo, aunque de forma todavía embrionaria, se asociará la actividad turística con el legado históricoartístico. Ya en 1887, en pleno inicio del interés por el turismo higienista, se funda el Museo Arqueológico, en el que se expone el primer sarcófago antropoide, aportando "un nuevo elemento de atractivo al visitante". MARCHENA: 96, p. 148. No obstante, el reclamo turístico principal en la primera mitad del siglo XX era la estación estival; así, en 1910, con el fin de potenciar el verano gaditano, se crea la Sociedad de Turismo. PIÑEIRO: 98, pp. 239-247.

22 Nótese en este sentido, que hasta un régimen tan claramente inclinado hacia el desarrollismo se permite considerar la necesidad de un "desarrollo ordenado y al mismo tiempo una conservación y cuidado de sus valores arquitectónicos". MINISTERIO DE LA GOBERNACIÓN: 48, p. 5.

23. Entre otras cosas porque los habitantes con menores ingresos del Casco Histórico rara vez viven en edificaciones de importante significación cultural-arquitectónica. En Cádiz se sigue manteniendo, grosso modo, la división socio-espacial ya vista para el siglo XIX (Nota 10). Sólo el Pópulo se mantiene como barrio de características monumentales y habitado por clases sociales populares.

24 Esta repentina política de carácter social puede relacionarse con la victoria del Partido Popular en las elecciones locales de ese año, que presagiaban una victoria en el ámbito nacional para el año siguiente, como, de hecho, ocurrió, con la consiguiente necesidad del PSOE de recabar votos. 
b) Normativa autonómica.

b.1) Decreto 238/1985 de 6 de Noviembre, enfocado hacia la rehabilitación arquitectónica y al fomento del empleo y a detener el proceso de expulsión de las clases menos favorecidas.

b.2) Decreto 202/1989 de 3 de Octubre. Se crea la figura de las "Barriadas de Actuación Preferente", referida a zonas especialmente deprimidas en función del hacinamiento, disgregación, marginalidad y delincuencia. Articulación integral de bienestar social. En Cádiz, se consideran Barriadas de Actuación Preferente: la Viña, Santa María y el Pópulo.

b.3) Decreto 51/1996 de 6 de Febrero. Entiende la rehabilitación como perteneciente exclusivamente a los elementos internos de la vivienda. Encontramos aquí concepción social y de habitabilidad, puesto que las intervenciones se fijan en función de ingresos familiares determinados.

c) Normativa municipal.

c.1) Ordenanza Municipal de ayuda a la rehabilitación de edificios residenciales. Concibe la rehabilitación como algo interior: condiciones mínimas de habitabilidad, adecuación, funcionalidad; pero también como algo externo: trabajos encaminados al mantenimiento del interés histórico, artístico o ambiental. Tiene, principalmente, carácter técnico.

c.2) Ordenanza Municipal de ayudas a la mejora del paisaje urbano. No exige requisito económico al beneficiario, otorga al ayuntamiento la potestad para requerir de forma obligatoria la rehabilitación de una fachada.

d) Directrices comunitarias.

DOCE, 94/C 180/02 de 1 de Julio de 1994. Es la denominada iniciativa URBAN; destinada a zonas comprendidas como objetivo $1^{\circ}$ (caso de Andalucía) que cumplan como características un tamaño mínimo de población y densidad, un porcentaje significativo de desempleo, y un tejido urbano deteriorado con malas condiciones de vivienda y falta de instalaciones sociales.

No admite ayudas para la rehabilitación de viviendas interiores por lo que, en principio, limita su actividad a las fachadas y al aspecto externo de las viviendas y los barrios.

Implica a los propietarios y aspira a carácter integrador: solución de problemas económicos, sociales y medioambientales con apoyo en las autoridades locales. ${ }^{25}$

e) De la fusión de la actividad local y de la europea surge el Plan URBAN-Cádiz del año 97. Este Plan se centra en los barrios de El Pópulo y Santa María, dos de los más afectados por problemas de marginación. Para resolverlos o paliarlos, se previó:

- Mejorar el soporte económico, reestructurando la actividad comercial y ofertando nuevas actividades terciarias con capacidad de innovación.

- Impulsar medidas de política social, facilitando formación que contribuya a la inserción profesional.

- Mejora de la escena urbana, de las condiciones de vida de la población y ambientales mediante la reducción de déficit de equipamientos, reurbanización de calles y modernización de redes de servicios. 
Todo ello a través de un conjunto de actuaciones que pueden encuadrarse en dos grandes líneas:

A) Actuaciones para la mejora del soporte físico y del espacio urbano:

o Mejora del medioambiente urbano.

o Programa de equipamientos dotacionales (sic).

B) Actuaciones para la mejora del soporte económico y del tejido social:

o Mejora del tejido económico.

o $\quad$ Programas de formación y empleo. ${ }^{26}$

Sin embargo, pese a fijar un objetivo doble, sólo ha dado buenos resultados en El Pópulo, a la sazón, más pequeño y con mayor legado histórico-cultural, y por tanto, más rentable de cara al turismo.

Como vemos, según el momento y la institución que legisle, se hace más hincapié en unos o en otros aspectos, y no siempre hay un interés social en las políticas de rehabilitación, más allá del que supuestamente ha de derivarse del desarrollo económico propiciado por el turismo, aunque no se tiene en cuenta que éste, a quien beneficia, es a las promotoras y a los empresarios del ramo, mientras que a la población sólo ofrece precariedad y temporalidad laboral.

\subsubsection{Vivienda y empleo}

A esta problemática planteada, se une la falta de financiación que acompañan a estas normativas y que, por tanto, las convierten, como se indicaba en la introducción, en papel mojado. Esta falta de financiación afecta especialmente a las políticas de rehabilitación de viviendas interiores. Sólo en caso de edificios declarados oficialmente en ruinas, la administración se decide a intervenir. Pero también afecta a la rehabilitación del entorno, por lo que se ha llegado al recurso a la cofinanciación de las obras entre las administraciones públicas, promotoras y propietarios. Esto repercute en tres niveles de beneficiarios: el edificio en sí, el propietario y otros poseedores de los medios de producción ${ }^{27}$, y por último, los habitantes.

Si comparamos los tres documentos base, los planes de 1948, 1984 y el Plan Urban de 1997, y apoyándonos igualmente en la obra de Acosta Seró, observaremos cómo la realidad no ha cambiado en demasía.

Los barrios más afectados ya en el Plan del $48^{28}$ son el Pópulo y, sobre todo, Santa María, al cual se le califica de insalubre; en el Plan del $84^{29}$, mucho más específico al respec-

http://www.cadizayto.es/urban/plan_urban_cadiz.htm

27 Hay que partir de la base de que en Cádiz, debido a la falta de suelo y a la carencia de un tejido industrial suficiente, las relaciones de producción, la explotación y las luchas de poder y el control sobre la población, se basan principalmente en la propiedad de fincas y terrenos.

28 En realidad el Plan del 48 no se extiende nada en la problemática social gaditana, demasiado elevada y poco conveniente de aireación para el régimen, que sólo se preocupaba de ella en tanto que posible, al menos en el discurso uniformizante, foco de subversión. Una reciente aportación al estudio de la población gaditana más humilde es la tesis de licenciatura de Moreno Tello: La clase obrera gaditana (1949-1959): una historia social a través de las fuentes populares. Aún inédita. Le agradecemos dejarnos consultarla.

29 El ayuntamiento del PSOE, sin embargo, pese a mejorar en muchos aspectos la ciudad y, de acuerdo con las leyes que rigen la rehabilitación, arreglar fachadas, mostró, en sus actuaciones, "poca incidencia en los problemas de vivienda". JIMÉNEZ y MALO: 95, p. 99. 
to, se realiza una clasificación de la vivienda atendiendo a una división entre los barrios populares y los del centro ${ }^{30}$. Los barrios populares abundan en casas pequeñas afectadas por el hacinamiento y la falta de higiene e incomodidad, y se clasifican en corrales, plantas iguales, casas por plantas y casas barrocas. Un tercio de las casas del centro sufren los mismos problemas, mientras que las de los otros dos tercios ${ }^{31}$ son amplias, confortables, higiénicas y cómodas.

El Plan URBAN, por su parte, declara que:

"El elevado índice de desempleo está en la raíz de las dificultades económicas que atraviesan muchas familias de la zona. Las rentas familiares son las más bajas del Casco Antiguo, el 33,6\% de las familias tiene una renta mensual inferior a las 10.000 pesetas.

La población activa presenta unos bajos niveles de cualificación profesional y la incorporación de la población femenina al mundo laboral es muy escasa.

Destaca la escasa presencia de empleo localizado en la zona por lo que esta se configura como dependiente y eminentemente residencial. La actividad económica gira en torno al muelle pesquero, la restauración y el hospedaje. La actividad comercial se caracteriza por su escasa especialización y está dedicada a productos de consumo diario." 32

Pese a la proliferación de establecimientos de hostelería en la zona y al innegable saneamiento y adecentamiento del barrio, no parece, por ahora, que la situación socioeconómica de los habitantes del mismo haya mejorado sustancialmente.

El libro de Acosta Seró analiza la situación socioeconómica de Cádiz y la relaciona con los distintos barrios. La continuidad que se aprecia entre el siglo XIX y el año 1998 es pasmosa.

En lo que respecta a los servicios urbanos: electricidad, agua, teléfono y otros elementos considerados básicos para el bienestar, e índices de desarrollo de una sociedad, ha habido grandes avances en los últimos 25 años. Pero son avances que poco o nada han tenido que ver con los planes específicos de acondicionamiento y rehabilitación de la ciudad, y sí mucho con el desarrollo de la sociedad de consumo.

Una cuestión esencial y derivada de estas problemáticas es el paulatino descenso de la población gaditana.

\subsubsection{Los transportes y las vías de comunicación}

Una de las cuestiones fundamentales para cualquier núcleo poblacional es la de constituir un buen sistema de comunicaciones y de transportes a su servicio. En relación con esto, hay que entender también el interés por las vías de acceso del año 48 (aunque sea como consecuencia del interés primordial). En este mismo texto se plantea la necesidad de mejorar $^{33}$ las vías interiores del Casco:

30 Recordemos que, como se ha indicado más arriba, hay que tener en cuenta la división que ya encontrábamos en el siglo XIX.

31 Estamos hablando aquí de casas habitadas; las que se hallaban vacías por ruina o especulación no formaron parte del estudio del Plan del 84.

32 http://www.cadizayto.es/urban/analisis_socieconomico.htm

33 Aunque "la reforma interior proyectada es mínima, pues por una parte la ciudad antigua con todo su valor histórico y tradicional merece un absoluto respeto y por otra parte las circunstancias presentes no permiten excesiva generosidad en las reformas interiores" (MINISTERIO DE LA GOBERNACIÓN: 48, p. 12). 
- Por un lado, se proyectó y realizó la conexión de Sacramento con Colón así como el ensanchamiento de Diego Arias a altura del Hospital San Rafael. El objetivo era crear dos ejes que partiendo desde el Puerto desembocaban en el Hotel Atlántico.

- La calle Sopranis se rectificó y ensanchó en su encuentro con la Cuesta de las Calesas.

- Se abrieron los arcos de Puerta de Tierra (al tiempo que se incluyeron los fososlugar utilizado poco antes como escenario de ejecuciones- en el espacio reservado para zonas verdes)

En el Plan de 1984, dada la multiplicación de los turismos, se plantean nuevas problemáticas:

- Se observa un número excesivo de entradas y salidas de tráfico rodado a la ronda periférica, entorpeciendo la circulación en la misma.

- Problema derivado de la excesiva presencia de coches particulares es la falta de aparcamientos. El atajo tomado por las distintas administraciones, dada la escasa voluntad de atacar a la raíz de un problema que es endémico y necesario hoy por hoy para el sistema capitalista (la industria de automóviles, la industria petroquímica y de hidrocarburos y el afán consumista que alimentan), es la proliferación de parkings ${ }^{34}$ subterráneos $^{35}$, que restan a la ciudad suelo edificable y que además ofrecen el frío espacio constituido por la arquitectura tecnofascista ${ }^{36}$. Un lado positivo de esta política es que, al menos, permitió la limitación del aparcamiento en algunas plazas y lugares públicos, por ejemplo, la Plaza de Pío XII.

- La abundancia y descontrol del tráfico rodado implica una carencia de seguridad y una merma en los derechos del peatón. En este documento se resaltan fundamentalmente tres: la falta de espacio alrededor del Mercado Central, los problemas derivados por la discontinuidad en Canalejas y Cuesta de las Calesas, y las dificultades de acceso a los espacios libres del borde (es decir, a las zonas de paseo junto al mar cruzando la ronda periférica). La principal resolución tomada en este sentido fue la creación de las zonas peatonales de las que aun hoy disfruta la ciudad.

- El transporte público. Se plantea reorganizarlo "para que aseguren (sic) un correcto servicio, dentro de márgenes de rentabilidad, de modo que este medio de transporte pase a ser competitivo con el vehículo privado." ${ }^{37}$ Es evidente que esto no se llevó a la práctica.

34 En relación con los parkings, no huelga comentar el del Paseo de Santa Bárbara, en reiteradas ocasiones proyectado como espacio abierto y de paseo (en el Plan del 84 se llega a plantear un paseo, frente al Hotel Atlántico, que conectase la Alameda con la playa de la Caleta sin perder de vista el mar): "únicamente conviene notar la necesidad de intervención en el paseo de Santa Bárbara” (AYTO DE CÁDIZ: 1984, p.44), y cuyo abandono por parte de la administración y cesión a la empresa que gestiona el parking nos brinda el espectáculo dantesco de su "conservación".

35 El proyectado en el plan del 84 es el del Campo del Sur. A este hay que unir, en tanto que construido en época de mayoría del PSOE en el Ayuntamiento, el de San Antonio.

36 Como puede constatarse en Extramuros en varias de las plazas-subterráneos construidas en los últimos años, que carecen de toda estética y de toda funcionalidad más allá de servir como tejado a ras de suelo a los aparcamientos construidos bajo tierra.

37 Ibíd. p. 63. 


\section{La integración de la Bahía. Algunos apuntes}

La provincia de Cádiz es un rara avis en lo tocante a su red urbana. Ésta está configurada por una gran cantidad de asentamientos, con tres centros subregionales (Algeciras, Cádiz-Bahía y Jerez de la Frontera) configurados en dos regiones urbanas polinucleares (en este sentido, Jerez y Cádiz suelen entenderse como un binomio). La región urbana Bahía de Cádiz-Jerez es la principal de la provincia y se distingue por distancias menores a los $25 \mathrm{~km}$ entre las localidades que la componen. En ella suelen diferenciarse, así mismo, tres ámbitos: Cádiz-Chiclana-San Fernando, Puerto Real-El Puerto de Santa María-Jerez, y el eje Sanlúcar-Chipiona-Rota (tres núcleos poblacionales, estos últimos, que gravitan sobre Jerez; como lo hacen sobre Cádiz los municipios de la Janda: Conil, Vejer y Barbate).

La Bahía, como tal, está constituida por la línea El Puerto de Santa María-Cádiz (con la extensión sur hacia Chiclana) como ámbito básico metropolitano. Así, Rota, municipio geográficamente perteneciente a la misma, queda excluido en los estudios específicos, principalmente en los encargados por la Administración.

La unidad de Cádiz con la Bahía del mismo nombre y con los núcleos poblacionales que con ella la comparten es una realidad histórica. Una realidad que ya pusieron en marcha los fenicios y que se expresa en el poblado de Doña Blanca ${ }^{38}$, que en la Edad Media tiene también su expresión en la unidad que Alfonso X da a la Bahía, dando cuerpo de peso a El Puerto de Santa María y a Cádiz, a la que fija, indudablemente, por su proyección hacia el océano, como cabecera de la misma. La ruptura de Cádiz con su hinterland se efectúa, sin embargo, poco después, cuando el mismo cae en manos señoriales, quedando sólo la capital como territorio de realengo ${ }^{39}$. A partir de ahí, le unirá más, en tanto que zona atlántica, el sino histórico, con la fachada del Golfo. Tanto más cuanto que la conquista de América abre a la ciudad, por su condición de puerto inmejorable, la posibilidad de destacarse como emporio. En la Edad Moderna, pues, se forjarán las controversias entre Cádiz y la Bahía, en concreto con El Puerto de Santa María, ligada esta población a los intereses vinateros de Jerez. Esta diferencia de intereses tendrá una serie de repercusiones, como, por ejemplo, la paralización de los proyectos ferroviarios que iban a convertir a la provincia de Cádiz en la primera en recibir una línea férrea (antes de la consabida Barcelona-Mataró).

En la actualidad, sin embargo, parece claro que, dado el proceso urbanístico a escala global y dados los nuevos retos económicos que plantea la mundialización, es momento de reiniciar el estrechamiento de relaciones entre los municipios de la Bahía, de enterrar los localismos que a poco fructíferos resultados conducen.

Iniciativas hay ya en este sentido; una de ellas es la poco eficaz Mancomunidad de la Bahía, que apunta a la estrecha relación de intereses de Jerez, vía El Puerto de Santa María, con Cádiz. Una comunidad de intereses sobre la que sin embargo, por ahora, prevalecen los egoísmos locales.

38 Sobre la localización de Gadir hay abierta una amplia polémica que, pese a su interés, se escapa de los objetivos de este estudio. Parece claro que una de las claves para arrojar luz sobre el tema es un estudio global y en profundidad sobre la Necrópolis gaditana. Sin embargo, la bibliografía al respecto es abundante y, a veces, contradictoria. Un reciente trabajo que intenta poner algo de concierto en el maremagno documental-bibliográfico es la tesis de licenciatura inédita de $\mathrm{M}^{\mathrm{a}}$ Vanessa Sibón Rodríguez: Nuevas aportaciones al estudio de la tipología funeraria de la Necrópolis fenico-púnica de Cádiz (s VII-III). Le agradecemos dejarnos consultarla.

39 Es de reseñar que Jerez de la Frontera, el otro gran núcleo que domina junto con Cádiz la región urbana comentada, también se mantuvo como territorio de realengo. 
En 1970, se presentó el Plan Comarcal de la Bahía de Cádiz, que proponía la creación de una ciudad lineal con extremos en Cádiz y Sanlúcar, y con El Puerto de Santa María y Jerez como eje central básico. La idea de partida de este plan era la necesidad de ordenar el expansivo sector turístico -recordemos que estamos refiriéndonos a la época del desarrollismo ${ }^{40}$ y unas "exageradas sobrevaloraciones del crecimiento demográfico y de los déficits de viviendas." ${ }^{41}$ Afortunadamente, tan descabellada idea no se llevó adelante, aunque, por otro lado, la falta de planeamiento en la era de la conurbación ha provocado, entre otras, la casi continuada línea de edificios entre El Puerto de Santa María y Rota.

El Plan de Ordenación del Territorio de la Bahía de Cádiz de 2002 (POT) no incluye a Jerez dentro de la Bahía, como sí hacen otras aproximaciones menos técnicas, como las relacionadas con la prensa ${ }^{42}$. No obstante, la referencia a este núcleo urbano es continua; téngase en cuenta la importancia del mismo como centro poblacional, por su aeropuerto, por su capacidad de crecimiento, y por su relación, antes mencionada, con municipios como El Puerto de Santa María.

Entiende este plan la Bahía como un todo homogéneo, altamente poblado y marcado por: ser un enclave portuario; su posición excéntrica en el territorio y su desarticulación regional; la presencia de núcleos urbanos medios (y la presencia de tres focos urbanos en competencia: Algeciras, Jerez y Cádiz, estos dos, sin embargo, unidos por intercambios comerciales); la estrecha relación de la zona noroeste (Chipiona, Sanlúcar y Rota) con la Bahía y Jerez ${ }^{43}$; los núcleos urbanos cuentan con un nivel de servicios y equipamientos que en niveles básicos cubren las necesidades de sus poblaciones, y esto resta movilidad entre los núcleos; la conurbación es ya una realidad ${ }^{44}$.

Uno de los problemas que acucian a la Bahía es la pésima red de comunicaciones ${ }^{45}$ (demasiado centralizada en Cádiz, por otra parte) y la mínima racionalidad del sistema público de transportes, en concreto de los autobuses, en manos de la compañía Comes y Carraca S.L., que como empresa casi monopolística se comporta con total desfachatez con el usuario.

La limitación del tejido ferroviario resulta especialmente incomprensible (desde una perspectiva que lo asuma como un bien público, y no bajo criterios de estricta rentabili-

El desarrollismo en España fue llevado a cabo siguiendo el modelo francés de planificación indicativa, pero a diferencia de en el país galo, donde su misión era clarificar los objetivos económicos a alcanzar, el Estado franquista lo presentó como la gran solución a todos los males, y se le privó de todo contenido estrictamente social.

${ }^{41}$ ZOIDO: 82 p. 111. En esta obra se trata también con cierta profundidad, pero con poco sentido crítico, la funcionalidad militar de la Bahía. Por considerarlo un poco fuera del marco trazado para la elaboración de este trabajo, se ha considerado preferible no extenderse en este sentido, aunque, al tiempo, por su importancia, he visto conveniente hacer, al menos, mención. De todas formas, la importancia histórica de lo militar en el proceso de configuración y poblamiento de la Bahía se evidencia, por ejemplo, tanto en el importante rol que le reserva Alfonso X a la ciudad, como en la misma fundación de los núcleos de Puerto Real (1493, para amarre de la flota de la Corona) y San Fernando (1751, destinataria de la nueva ubicación del Departamento de Marina trasladado desde Cádiz).

42 Por ejemplo el periódico digital Bahía de Cádiz. O como la misma "Mancomunidad de la Bahía”, que incluye los municipios de Cádiz, Chiclana, Jerez, Puerto Real, El Puerto de Santa María, Rota y San Fernando.

43 En concreto, las relaciones entre la Bahía, Rota y Jerez se articulan en torno a la existencia de servicios urbanos comunes.

44 Corredores El Puerto de Santa María-Jerez, El Puerto de Santa María-Rota, Cádiz-Puerto Real y San Fernando-Chiclana.

45 A la que habría que sumar la inexplicable desconexión ferroviaria y con carreteras decentes con La Janda y con el Campo de Gibraltar. La reciente Autovía Jerez-Los Barrios (A-381) ha mejorado algo la situación en este sentido. 
dad económica). Y no sólo en lo tocante a la Bahía (la nunca creada conexión ChiclanaSan Fernando ${ }^{46}$ y el suprimido enlace Sanlúcar-El Puerto de Santa María ${ }^{47}$ ), sino también en relación a la integración de la provincia en su conjunto. Varios son los proyectos, evidentemente no llevados a término, de conexión, vía La Janda, de las dos bahías.

Por otro lado, aún se está proyectando el desdoblamiento de la vía férrea Cádiz-Jerez.

Una opción fiel a la tradición marítima de los municipios de la Bahía y a su propia constitución como ente histórico coherente es la de la potenciación de líneas de transporte público marítimo por la Bahía ${ }^{48}$, que vengan a sumar fuerza con el elemento residual y sentimental que supone el célebre Vaporcito. Una línea regular que calase en todos los puertos de la Bahía es la solución sin duda para descongestionar el puente y las carreteras, así como para favorecer la movilidad entre las distintas localidades de la misma. En la actualidad, siguiendo el trazado viario, un habitante de Rota tarda alrededor de una hora en recalar en Cádiz. Un transporte de calidad cruzando la Bahía, aún sin trayectos directos entre localidades sino mediante un recorrido de una a otra, podría aminorar en una media hora el tiempo del recorrido.

La Bahía de Cádiz ha necesitado de hecho, para integrarse y para salir de la situación de estancamiento y paro estructural que la acucia, de la configuración de una zona portuaria coordinada por todos los municipios que la circundan, un puerto único ${ }^{49}$. En dicha zona portuaria, coordinada por la Autoridad Portuaria de la Bahía de Cádiz, en función de sus particulares características cada puerto tiene una función concreta. Así, en el muelle de la Cabezuela se está concentrando la mayor parte del tráfico de graneles sólidos, mientras los líquidos arriban a Cádiz y la actividad pesquera encuentra cobijo en ésta y en El Puerto de Santa María. El puerto de Cádiz se está mostrando idóneo para recibir contenedores y hoy es la principal punta de lanza del tráfico Ro-Ro con las islas Canarias (y uno de los punteros, a nivel industrial, en cuanto al Off-shore). También tiene un importante potencial como lugar de atraque para barcos turísticos (función que comparte con El Puerto de Santa María). Con todo ello, parece evidente, dada la situación de paro estructural y huída laboral de la población gaditana ${ }^{50}$, que es necesaria una mayor

46 En el POT 2002, la conexión propuesta es Puerto Real-Chiclana. El proyecto tendría una doble funcionalidad: integración de Chiclana y El Marquesado en la red de cercanías de la Bahía de Cádiz, y enlace intermodal entre el puerto de ésta y el puerto de Algeciras.

47 A comienzos de los años 80, este tramo era recorrido tan sólo por un convoy en cada sentido al día, pero se pretendía aun mejorarlo en lugar de eliminarlo, lo cual efectivamente se acabó haciendo.

48 Que, junto al desarrollo de las vías férreas, vendría, además, a dar cuerpo a las declaraciones de intención de la Unión Europea y del Estado español: "Dado el aumento continuo del volumen de tráfico, son necesarias estrategias integradas (...) debe tenerse en cuenta el menor impacto medioambiental del ferrocarril, las vías fluviales y el transporte marítimo." CEMAT: 2000, p.16.

49 Evidentemente no cifrar todas las esperanzas de crecimiento económico, y más como cuando es el caso la crítica a esta tendencia se realiza desde una perspectiva social, en el sector servicios, no implica asunción del industrialismo y mucho menos la recaída en la política industrial desarrollista, que básicamente reclamó los ahorros de otros sectores (que sufrieron descapitalización al no gozar de reinversiones), buscó más el crecimiento sectorial que la articulación del territorio y llegado el momento, como fue ya comentado para Cádiz y Andalucía, debido a la importancia mayor de las rentas del suelo respecto a otros países de economía más equilibrada, la búsqueda de esta vía de rentabilidad fue la más perseguida por el capital, convirtiéndose la recalificación del terreno en un fin perseguido en sí mismo. Sigo pues a Zoido cuando afirmaba que el desarrollo de las capacidades productivas de Andalucía pasa por la industrialización "pero no por cualquier industrialización ni por la consecución de ésta a cualquier precio". ZOIDO: 82, p. 174.

50 Al problema que, particularmente aqueja a la población de la Bahía, hay que añadirle el rumbo tomado por la economía libre en tanto que la desmoralización y despolitización de gran parte de la sociedad, unidas al desarrollo 
profundización en la cohesión de la Bahía, y al tiempo en la de los puertos con las poblaciones en las que se encuentran. Barragán critica, en referencia a los proyectos (y en particular a los no realizados) de ingeniería portuaria que "la integración de los proyectos portuario-industriales con las ciudades de la Bahía casi no existe." ${ }^{51}$ Zoido, por su parte, criticaba en 1980 el continuismo de los responsables de las autoridades portuarias, y de la estructura de las mismas, desde el franquismo. ${ }^{52}$ Que en la actualidad hay una notable desconexión entre el puerto de la Bahía y la población a la que en teoría sirve ${ }^{53}$ lo demuestra, no sólo la baja relación de empleo que genera, sino el propio desconocimiento por parte de una importante fracción de la población sobre la existencia de una Autoridad Portuaria regente sobre toda la Bahía, y sobre las funciones precisas que ejerce y corresponden a la Zona Franca de dicho puerto.

El recinto Franco, fuera de las polémicas recientes, curiosamente no ha satisfecho las expectativas en él colocadas por tantas generaciones. Después de que las administraciones públicas descartaran a comienzos del siglo XX la conversión en su totalidad del puerto gaditano en territorio libre de tasas, fueron acumulándose proyectos, ya faraónicos, ya razonables, para el aumento del físico del mismo, y en cuanto a la configuración de alguna de sus zonas como Zona Neutral o Franca. De estas elucubraciones, así como de los resultados prácticos de algunos de ellos, nos da buena cuenta y relación Barragán ${ }^{54}$. La ubicación final del recinto franco en Puntales se debió al abrigo que ofrece, al escaso calado de la zona a rellenar y a la superficie disponible para las posibles ampliaciones. Sobre su tamaño, como se ha indicado, se idearon múltiples proyectos, que unas veces por falta de presupuesto y otras por mera imposibilidad no se llevaron a cabo. En relación a esto, merece sea indicado cómo la significación gaditana como área estratégica, y por tanto, con importante presencia militar, ha significado también un handicap para el desarrollo económico de la zona ${ }^{55}$. En 1961, el Ministerio de la Marina impidió el crecimiento del puerto (proyectado por el de Obras Públicas, que pretendía prolongar el Muelle de Poniente), a través del "Proyecto de delimitación del puerto de la Zona Franca" para instalar la "Base de la Agrupación Anfibia de la Marina de Guerra", en Puntales ${ }^{56}$.

Como se indicaba, la Zona Franca no da satisfacción a día de hoy a las esperanzas de la población, y más bien se constituye, en este sentido, en un verdadero fracaso. Un fracaso que se ve incrementado por el triunfalismo absurdo con el que, por ejemplo, se anun-

de las nuevas tecnologías, se lo permiten; esto es: la flexibilidad del mercado laboral, la subcontrata, la movilidad e inestabilidad del trabajador y la deslocalización. El subempleo, y su capacidad para desestructurar las antiguas formas de producción, creando así el terreno ideal para impedir el florecer de formas de organización y lucha colectiva en los puestos de trabajo.

51 BARRAGÁN: 95, p. 99. En esta misma obra, critica también la "identificación del potencial portuario con las actividades comerciales, industriales y defensivas" (Ibíd.). Ciertamente, reclamar un mayor papel para el puerto de la Bahía en el tráfico mundial de mercancías y pasajeros, y un mayor protagonismo en la industria como creadora de empleo en la provincia, no debe conducir a desvaríos desarrollistas.

52 ZOIDO: 82, p. 140.

53 Sobre este asunto también mostraba su interés el Cabildo de 1984, que marcaba como objetivo de su Plan la "reintegración del equilibrio puerto-ciudad, que posibilite la apertura del primero a la vida local" (AYTO DE CÁDIZ: 1984, p.9). Ruiz Navarro, por su parte, ahonda en la necesaria integración y coordinación política y económica de los puertos y cabildos de la Bahía y en relación con la Zona Franca (RUIZ: 87, pp. 165-166). BARRAGÁN: 95.

Y para la extensión urbana. Recordemos las discusiones en torno a la "Zona-Polémica". Ibíd. p. 61. 
cia la conversión de una parte del recinto en muelle deportivo, cuando sería más conveniente reflexionar acerca de porqué unos terrenos destinados en principio a la actividad industrial y mercantil, terminan asumiendo funciones de esparcimiento para las capas beneficiadas de la sociedad.

Los contenedores, uno de los puntales de la actividad portuaria, habrían de tener salida directa hacia el continente, bien por vía férrea (y el soterramiento ha creado las condiciones oportunas) bien a través de una carretera exterior (recordemos que, en el Plan del 47, ésta era la misión encomendada a la, por ello denominada, carretera industrial). Por supuesto, esto tendría que verse facilitado con la supresión total del peaje en la autopista Cádiz-Sevilla, verdadera lacra para el desarrollo económico y social de la provincia.

Es evidente que uno de los errores, con o sin intención según las opiniones, de las administraciones públicas fue el de acreditar al de Cádiz como puerto de primera, con la sobrecarga de peaje que supone para los barcos su atraque en el mismo. Esta decisión desvió, ineludiblemente, el tráfico marítimo hacia el puerto de Algeciras. La posible y deseable mejoría de la actividad del puerto de la Bahía no tendría efectos perniciosos relevantes sobre esta localidad del Estrecho, que ya tiene su mercado y está indudablemente mejor situada, por su cercanía a Gibraltar y por su situación, para la recepción de los barcos provenientes del Magreb y del resto de la cuenca del Mediterráneo. Una modificación en profundidad y mejora del Puerto de la Bahía de Cádiz al que afectaría es al puerto de Sevilla, beneficiado hasta ahora, ilógicamente y en detrimento del primero, por el centralismo estatal y de la Junta. Y esto cuando el río Guadalquivir presenta ostensibles problemas para los buques (las barras de arena que ya hicieron trasladar a Cádiz la Cabecera de Comercio-1680- y la Casa de Contratación-1717-, o la estrechez de las esclusas, que perjudican gravemente la estructura externa de los barcos de mayor calado y manga) y cuando la propia existencia del Puerto fluvial es perjudicial para el río y para el ecosistema de Doñana, ya que saliniza las aguas y las marismas (además de la inevitable contaminación fruto del trasiego de buques ${ }^{57}$ ). Sin embargo, la administración, en lugar de fomentar el, en potencia, mucho más rentable y ya equipado, complejo industrial portuario de la Bahía de Cádiz (industrial, porque, indudablemente, la reactivación de la actividad portuaria a gran escala sería un gran empuje ${ }^{58}$ para el mantenimiento de industrias como la de astilleros ${ }^{59}$ ), se plantea en la actualidad proyectos de ampliación del puerto fluvial sevillano ${ }^{60}$.

57 Acerca de los efectos nocivos del puerto sevillano sobre el río Guadalquivir y el Parque Nacional de Doñana, es abundante la información en internet, sobre todo en cuanto a las implicaciones de las obras de ampliación y dragado: http://www.losverdesdeandalucia.org/ noticia.php?id=9314\&numero=1020, http:/ /www.losverdesdeandalucia.org/enviarnoticia.php?id=2858, http://www.wwf.es/noticia.php?codigo=359; http://ania.eurosur.org/noticia.php3?id=760

58 Impulso no sólo para las plantas industriales en declive, sino también para aquellas hoy pujantes y con proyección de futuro: las ya mencionadas instalaciones de Dragados Offshore, la planta de Airbus. Como ejemplo del carácter de factor de localización industrial (ya como terminal, ya como núcleo modal) de los puertos, tenemos la cementera de la Cabezuela, fruto del trasiego de graneles sólidos en este muelle.

59 Ante la complicada situación que vive el sector naval en la actualidad, es de reseñar y objeto de reflexión que el mismo problema viene arrastrándose desde hace décadas. Así, en 1983, como camino para el afianzamiento del sector naval ya se apuntaba, como de hecho, venía haciéndose, a "la vía política de apoyo financiero para la consecución de cartera de pedidos" (AAVV: 83, p. 329), lo cual es prueba del sentido social, más que económico, que posee la industria naval en la Bahía.

60 El proyecto de ampliación de los accesos al Puerto de Sevilla incluye la construcción de una nueva esclusa y el dragado del canal de navegación del río Guadalquivir. Estas obras aumentarán los problemas ecológicos que plantea 


\section{Conclusiones. Futuro inmediato y a medio plazo de la ciudad}

De la comparativa entre los tres documentos base utilizados, parece clara la continuidad de los problemas sociales. Es más, esta situación, dado el actual desmantelamiento del Estado del Bienestar y la paulatina caída en manos privadas y sin control de todo el tejido económico (con lo que implica en cuanto a la poca atención al interés público, cifradas siempre las actuaciones según criterios de rentabilidad e incremento de la riqueza; y con lo que representa también en cuanto a reproletarización de la ciudadanía-consumidores) no parece que tenga visos de mejorar sino todo lo contrario.

Ante ello, se presentan dos alternativas. Bien una poco probable, al menos en un tiempo corto, revolución social por la que la ciudadanía tome en sus manos los resortes del poder, bien el mantenimiento de la estructura capitalista con una mayor o menor injerencia del Estado según los ritmos marcados por el mercado y la situación internacional. Lamentablemente, pueda el Estado o no intervenir en el sino de la provincia, de la Bahía y de la ciudad, éstas tienen ya adjudicadas un determinado rol o función socioeconómica en la sociedad globalizada y, en concreto, dentro de la UE: servir de destino turístico y residencia última a los jubilados centroeuropeos. En este sentido, probablemente, pocas intervenciones e iniciativas se llevarán a cabo que no estén destinadas a rentabilizar esta situación, con los problemas de dependencia y estacionalidad y sufrimientos que para la población local representa. Probablemente, el desarrollo futuro del urbanismo en Cádiz se realizará en función de estas variables. Difícilmente veremos una reindustrialización de la zona, y tampoco la profundización en una zona portuaria integral y coherente en sí misma y con respecto a las núcleos urbanos que le dan cobijo $^{61}$ (es más, se hará todo lo posible por dividir y marginalizar, en todos los sentidos, a las poblaciones de la Bahía). Sin embargo, ya estamos viendo cómo se va a construir un segundo puente ${ }^{62}$, sin contar demasiado con el impacto ecológico ${ }^{63}$ o con medidas más racionales como el transporte por la Bahía mediante ferries ${ }^{64}$, que no por casualidad tiene su salida proyectada, justo, junto al Corte Inglés.

La vivienda, junto con el desempleo y el subempleo, se configura como uno de los problemas esenciales de la ciudad. Por las características de la misma, tiene un calado muy superior al que de por sí la especulación urbana y el boom de la construcción tienen en el

el puerto sevillano; según ADENA:"Los dragados proyectados al servicio del Puerto de Sevilla provocarán erosión de las márgenes, salinización del estuario y vertido de sedimentos en áreas de alto valor." www.wwf.es/ descarga/descarga_genetsis/FACTSHEET_Bigjump.pdf

61 No obstante lo que decimos, durante el ejercicio 2004, el puerto de la Bahía de Cádiz (principalmente en lo que respecta a graneles sólidos -la Cabezuela-) fue el cuarto puerto en crecimiento del Estado. Sin embargo este aumento del tráfico no se hace notar sobre el conjunto de la población gaditana. http://www.masmar.com/noticias/ html/ 34068.html

62 La aspiración acerca de la consecución del tercer acceso, no sólo es bastante añeja -ya en el año 1983 se proponía (AAVV: 83)-, sino que cada vez se presta más a la duda que su construcción vaya a comenzar en un tiempo tan cercano como la propaganda oficial nos hace creer. Es posible que simplemente se una al listado de proyectos monumentales no llevados a cabo que tan prolíficos han sido en la literatura urbanística de la Bahía.

63 http://www.nodo50.org/ecologistas.cadiz/EACadiz/sitioEACadiz/3acceso_no.html

64 Recientemente se ha llegado a un acuerdo, entre la empresa Trampsa, la Consejería de Obras Públicas y el Consorcio Metropolitano de Transportes, para poner en marcha en octubre dos catamaranes que conectarán Rota, Cádiz y El Puerto de Santa María con un tiempo máximo de recorrido de media hora. http://www.elpais.es/ articulo.html?xref=20050721elpand_21\&type=Tes\&anchor=elpepiautand 
conjunto del Estado. De hecho, la limitación del espacio edificable no da pie a esa forma de especulación y conforma a esta última en la modalidad ya reseñada de concentración y paralización del mercado por parte de los asusta viejas. La salida a este atolladero, y a falta de una decidida intervención política, pasa inevitablemente por dos premisas: la organización ciudadana y la ruptura de la barrera psicológica localista, en pos, nuevamente, del reconocimiento de la coherencia interna, y de cara al exterior, que corresponde a la Bahía. Aquí nuevamente, encontramos el impedimento propiciado por la falta de voluntad política y su ligazón con los intereses de los capitalistas y oligarcas locales y regionales. Sólo mediante una prioritaria unidad de acción de índole socioeconómica, en la cual participe la población, y que supere el restringido marco de la terciarización designado a la provincia, podrá subvertirse la situación actual de precariedad e indefensión de nuestra sociedad.

\section{FUENTES Y BIBLIOGRAFIA}

AAVV: Estudio Económico de la Provincia de Cádiz, Cádiz, Diputación de Cádiz, 1983.

AAVV: Andalucía: Sistemas de Ciudades, Tomo I, Sevilla, Junta de Andalucía, 1986.

AAVV: $H^{a}$ de Cádiz, IV Vol., Cádiz, Diputación de Cádiz, 1991.

AAVV: Paisaje urbano y memoria. La ciudad de Cádiz en el siglo XX. Cádiz, Ayuntamiento de Cádiz, 2002.

AAVV: Los Proyectos de Papel. Cádiz, Junta de Andalucía, Consejería de Cultura, 2003.

ACOSTA SERÓ, M: Política de Rehabilitación Urbana y Entorno Económico en el Casco Antiguo de Cádiz. Cádiz, UCA, 1998.

AUTORIDAD PORTUARIA DE LA BAHÍA DE CÁDIZ: Puerto de la Bahía de Cádiz, sin fecha.

AYTO DE CÁDIZ: Plan Especial de Protección y Reforma del Interior del Casco Antiguo de Cádiz, Ayuntamiento de Cádiz, 1984.

BARRAGÁN MUÑOZ, J.M: Puerto, ciudad y espacio litoral en la Bahía de Cádiz, Salamanca, Autoridad Portuaria de la Bahía de Cádiz, 1995.

CONFERENCIA EUROPEA DE MINISTROS RESPONSABLES DE ORDENACIÓN DEL TERRITORIO (CEMAT): Principios Directores para el Desarrollo Territorial Sostenible del Continente Europeo, Madrid, Ministerio de Medio Ambiente, 2000.

CONSEJERÍA DE OBRAS PÚBLICAS Y TRANSPORTE: Plan de ordenación del territorio de la Bahía de Cádiz, Sevilla, Junta de Andalucía, 2002.

FERIA TORIBIO, J. M: "El papel de la promoción pública en la configuración de la oferta de suelo industrial en Andalucía" La indústria en la planificació urbana. V Jornadas de Geografía Industrial. Girona, Universitat de Girona, 1994 (pp. 57 66).

FONTANA, J (ed.): España bajo el Franquismo, Barcelona, Crítica, 1986. 
GARCÍA GUTIÉRREZ, A: Medios de fomentar el desarrollo comercial industrial y marítimo de Cádiz, 1895. Cádiz, Edición de Juan Manuel Barragán y Juan Torrejón, 1995.

JIMÉNEZ MATA, J. y MALO de MOLINA, J: Guía de Arquitectura de Cádiz. Cádiz, Consejería de Obras Públicas y Transportes y Colegio Oficial de Arquitectos de Andalucía Occidental, 1995.

MARCHENA DOMÍNGUEZ, J: Burgueses y caciques en el Cádiz de la Restauración. Cádiz, UCA, 1996.

MINISTERIO DE LA GOBERNACIÓN. DIRECCIÓN GENERAL DE ARQUITECTURA (Urbanismo): Plan General de Ordenación de la Ciudad de Cádiz. Extracto de la Memoria. Cádiz, 1948.

MORENO TELLO, J. S: La clase obrera gaditana (1949-1959): una historia social a través de las fuentes populares. Tesis de licenciatura. Inédita.

OCAÑA OCAÑA, C: La actividad en el espacio urbano. Málaga, UMA, 1998.

PIÑEIRO BLANCA, J. M: Ramón de Carranza. Un oligarca gaditano en la crisis de la Restauración. Cádiz, UCA y Diputación de Cádiz, 1998.

PLAN URBAN-CÁDIZ, 1997. http://www.cadizayto.es/urban/analisis_sociecono mico.htm

RUIZ NAVARRO, J: La Bahía de Cádiz: Reconversión y Reindustrialización. Cádiz, Diputación de Cádiz, 1987.

- La Bahía de Cádiz. Un área metropolitana industrial en el contexto de Europa. Cádiz, Cámara Oficial de Comercio e Industria y Navegación de Cádiz, 1993.

SIBÓN RODRÍGUEZ, M. V.: Nuevas aportaciones al estudio de la tipología funeraria de la Necrópolis fenico-púnica de Cádiz (s VII-III). Tesis de licenciatura. Inédita.

SUÁREZ JAPÓN, J. M: El derribo de las murallas de Cádiz. Madrid, 1999.

TROITIÑO VINUESA, M. A: Cascos Antiguos y Centros Históricos: problemas, políticas y dinámicas urbanas, Madrid, Ministerio de Obras Públicas y Transporte, 1992.

VILAR, P: Historia de España, Barcelona, Crítica, 2004.

ZOIDO NARANJO, F: Bahía de Cádiz, bases para la coordinación del planeamiento urbanístico. Cádiz, Diputación de Cádiz, 1982. 